\title{
Rapid and reliable genotyping of polymorphic loci modifying correct splicing of CFTR pre-mRNA using mass spectrometry
}

\author{
André Schaller ${ }^{1,3}$, Thomas von Känel ${ }^{1,3}$, Benedikt $\mathrm{Gehr}^{2}$, Javier Sanz ${ }^{1}$ and Sabina Gallati ${ }^{\star 1}$ \\ ${ }^{1}$ Division of Human Genetics, University of Bern, Bern, Switzerland; ${ }^{2}$ Institute of Biochemistry and Molecular Biology, \\ University of Bern, Bern, Switzerland
}

We describe a fast and unambiguous method for haplotyping the (TG)mTn repeat in IVS8 and determining three other single nucleotide polymorphisms (SNPs) in exons 10, 14a and 24 in the cystic fibrosis transmembrane conductance regulator (CFTR) gene affecting correct splicing of the CFTR pre-mRNA using primer extension and mass spectrometry. The diagnostic products are generated by primer extension $(P E X)$ reactions, which require a single detection primer complementary to a region downstream of a target strand's variable site. On addition of a polymerase and an appropriate mixture of dNTP's and 2', $3^{\prime}$-dideoxynucleotide triphosphates (ddNTP's), the primer is extended through the mutation region until the first ddNTP is incorporated and the mass of the extension products determines the composition of the variable site. Analysis of patient DNA assigned the correct and unambiguous haplotype for the (TG)mTn repeat in intron 8 of the CFTR gene. Additional crucial SNPs influencing correct splicing in exon 10, 14 and 24 can easily be detected by biplexing the assay to genotype allelic variants important for correct splicing of the CFTR pre-mRNA. Different PEX reactions with subsequent mass spectrometry generate sufficient data, to enable unambiguous and easy haplotyping of the (TG)mTn repeat in the CFTR gene. The method can be easily extended to the inclusion of additional SNPs of interest by biplexing some of the PEX reactions. All experimental steps required for PEX are amenable to the high degree of automation desirable for a high-throughput diagnostic setting, facilitating the work of clinicians involved in the diagnosis of non-classic cystic fibrosis.

European Journal of Human Genetics (2007) 15, 53-61. doi:10.1038/sj.ejhg.5201725; published online 4 October 2006

Keywords: cystic fibrosis; CFTR; MALDI-TOF; SNP; haplotyping; pre-mRNA splicing

\section{Introduction}

Cystic fibrosis (CF), the most common autosomal recessive disorder in Caucasians, is caused by mutations in the cystic fibrosis transmembrane conductance regulator (CFTR) gene. More than 1300 mutations and polymorphisms of

${ }^{*}$ Correspondence: Professor S Gallati, Division of Human Genetics, University Children's Hospital, Inselspital, Freiburgstr., Bern CH-3010, Switzerland. Tel: +4131632 95 48; Fax: + 413163294 84;

E-mail: sabina.gallati@insel.ch

${ }^{3}$ These authors contributed equally to this work.

Received 16 May 2006; revised 22 August 2006; accepted 30 August 2006; published online 4 October 2006 the gene have been reported so far, including the dinucleotidic (TG)m repeat and the adjacent polythymidine IVS-8-T tract Tn located in the acceptor splicing site of intron 8.

The number of (TG) dinucleotides varies from 8 to 13 , whereas six allelic variants of the Tn repeat with 3T, 5T, $6 \mathrm{~T}, 7 \mathrm{~T}, 9 \mathrm{~T}$ and $10 \mathrm{~T}$ have been found so far, with the 3T, 6T and $10 \mathrm{~T}$ alleles being extremely rare forms. ${ }^{1-6}$ It has been previously shown that the correct splicing of CFTR exon 9 strongly depends on the length of the Tn tract: with decreasing length of the tract, the proportion of CFTR transcripts lacking exon 9 increases, leading to 
dysfunctional CFTR proteins. ${ }^{1}$ The 5 T allele is associated with various clinical manifestations; individuals bearing a $5 \mathrm{~T}$ allele in trans with a severe CF-causing mutation may present with nonclassic CF or congenital bilateral absence of the vas deferens (CBAVD), whereas about $40 \%$ may be healthy and fertile. ${ }^{7-9}$ This incomplete penetrance of the $5 \mathrm{~T}$ allele as disease mutation presents a problem in genetic testing, as long as the factors affecting penetrance are not understood. Yet, there is growing evidence that the (TG)m repeat preceding the $\mathrm{Tn}$ tract has a major impact on the clinical manifestation of the 5T allele. A recent study demonstrated that individuals with $5 \mathrm{~T}$ adjacent to either 12 or 13 (TG) repeats are substantially more likely to exhibit an atypical CF phenotype than those with 5T adjacent to 11 (TG) repeats. ${ }^{10}$ This finding is supported by studies proving a positive correlation between the length of the (TG)m repeat and the proportion of exon 9 skipping. ${ }^{11,12}$

Several methods for the analysis of the polymorphic (TG)mTn locus have been proposed, including multistep sequencing with biotinylated primers and/or radioactive sequencing ${ }^{13-15}$ or the analysis of denaturating gradient gel electrophoresis (DGGE) patterns characterized by direct sequencing, ${ }^{6,16,17,10}$ as well as a two-step procedure using nested PCR and $X m n I$ digest $^{7}$ for the analysis of the Tn tract and subsequent determination of the (TG)m repeat by direct sequencing. ${ }^{18,19}$ Alternatively, both the (TG)m repeat and Tn tract are assessed simultaneously by sequencing. ${ }^{10,20}$ However, sequencing-based methods have the drawback that data interpretation may be difficult and time consuming due to shifts in electropherograms caused by heterozygosity for one or both repeats. In addition, microdeletions neighbouring the (TG)mTn repeat (like 1342-2delAG, 1366delG, 1367del5 and 1367delC) may further complicate the assessment of the (TG)mTn repeat as they lead to additional shifts in electropherograms.

An alternative to the methods mentioned before is matrix-assisted laser-desorption ionization time-of-flight mass spectrometry (MALDI-TOF MS), which has been widely used for genetic analyses over the last few years. ${ }^{21,22}$ The extremely short analysis time combined with the possibility for both, multiplexing and automation, allow accurate and cost-effective high throughput analysis of mutations, single nucleotide polymorphisms (SNPs) and variable length polymorphisms. ${ }^{23}$ Several researchers applied these advantages for CFTR mutation screenings by developing MALDI-TOF MS-based protocols for the analysis of up to 100 CFTR mutations including the polymorphic Tn tract in intron 8 , yet not the preceding (TG)m repeat. $^{24,25}$

In this proof of principle study, we developed a MALDITOF MS-based assay for the rapid and compelling determination of the (TG)mTn polymorphic locus in CFTR intron 8. The assay is convenient for clinical testing at highthroughput level and represents at the same time the first MALDI-TOF MS-based method for the determination of (TG)mTn haplotypes including a detection system for three SNPs $(1540 A>G, 2694 \mathrm{~T}>\mathrm{G}$ and $4521 \mathrm{G}>\mathrm{A})$ that have been shown to be involved in alternative splicing mechanisms and as a consequence in the development of CF-like phenotypes. $^{26}$

\section{Materials and methods \\ DNA sample preparation and PCR}

Twenty patients were chosen from a group of individuals with suspicion of nonclassic CF in which the CFTR gene including the (TG)mTn repeat had been analysed according to the protocol published by Liechti-Gallati et al. ${ }^{27}$ Individuals were chosen to represent a broad range of (TG)mTn geno- and haplotypes. Genomic DNA was extracted from EDTA-blood using the Qiagen blood DNA isolation kit according to the manufacturer's protocol. The study protocol was approved by the local ethic committee and all patients gave written consent to this study.

Exons and exon-intron boundaries of the CFTR gene containing the variants of interest were amplified using the primers reported by Zielenski et $a l^{28}$ with exception of primers $\mathrm{CF}_{2} 4 \mathrm{~B}^{27}$ and $\mathrm{CF} 24 \mathrm{~A}$, which were designed using Oligo software v6.0 (Molecular Biology Insights, Inc.) (Table 1). The standard PCR protocol was carried out in $25 \mu \mathrm{l}$ reaction mixtures containing $300 \mathrm{ng}$ DNA, $1.2 \mu \mathrm{M}$

Table 1 PCR primer sequences used for geno- and haplotyping of CFTR polymorphism

\begin{tabular}{|c|c|c|c|}
\hline CFTR polymorphism & Primer & Sequence $\left(5^{\prime} \rightarrow 3^{\prime}\right)$ & $P C R$ length $(b p)$ \\
\hline (TG)mTn (IVS8) & $\begin{array}{l}\text { CF9A } \\
\text { CF9B }\end{array}$ & $\begin{array}{l}\text { TAA TGG ATC ATG GGC CAT GT } \\
\text { ACA GTG TTG AAT GTG GTG CA }\end{array}$ & 560 \\
\hline $1540 A>C(\operatorname{ex~10)}$ & $\begin{array}{l}\text { CF10A } \\
\text { CF10B }\end{array}$ & $\begin{array}{l}\text { GCA GAG TAC CTG AAA CAG GA } \\
\text { CAT TCA CAG TAG CTT ACC CA }\end{array}$ & 492 \\
\hline $2694 \mathrm{~T}>\mathrm{G}(\operatorname{ex~14a)}$ & $\begin{array}{l}\text { CF14aA } \\
\text { CF14aB }\end{array}$ & $\begin{array}{l}\text { AAA AGG TAT GCC ACT GTT AAG } \\
\text { GTA TAC ATC CCC AAA CTA TCT }\end{array}$ & 502 \\
\hline $4521 \mathrm{G}>\mathrm{A}(\mathrm{ex} 24)$ & $\begin{array}{l}\text { CF24A } \\
\text { CF24B }\end{array}$ & $\begin{array}{l}\text { AGG CTC TGG ACA TTG CAT T } \\
\text { CGA GCT CCA ATT CCA TGA GG }\end{array}$ & 359 \\
\hline
\end{tabular}


primer mix for genotyping the (TG)m and (TG)mTn repeat and $2.4 \mu \mathrm{M}$ for genotyping all other polymorphisms, $1.25 \mathrm{U}$ Taq polymerase (Roche), $0.2 \mathrm{~mm}$ of each dNTP and $1.5 \mathrm{mM}$ $\mathrm{MgCl}_{2}$ except for amplification of the $2694 \mathrm{~T}>\mathrm{G}$ and $4521 \mathrm{G}>\mathrm{A}$ locus, where $5.5 \mathrm{mM} \mathrm{MgCl}_{2}$ was included.

PCR conditions were $95^{\circ} \mathrm{C}$ for $2 \mathrm{~min}$ followed by 35 cycles (40 cycles for $2694 \mathrm{~T}>\mathrm{G}$ and $4521 \mathrm{G}>\mathrm{A}$ locus) of denaturation at $95^{\circ} \mathrm{C}$ for $15 \mathrm{~s}$, annealing at $61^{\circ} \mathrm{C}$ for $15 \mathrm{~s}$ extension for $45 \mathrm{~s}$ at $72^{\circ} \mathrm{C}$ and termination by $5 \mathrm{~min}$ incubation at $72^{\circ} \mathrm{C}$. Using $5.5 \mathrm{mM} \mathrm{MgCl}_{2}$ and 40 cycles were found to be optimal for the pre-existing primer pairs to biplex the $2694 \mathrm{~T}>\mathrm{G}$ and $4521 \mathrm{G}>\mathrm{A}$ loci using $61^{\circ} \mathrm{C}$ annealing temperature. Amplification was achieved using a
9700 Thermocycler (PE Applied Biosystems). To remove excess primers, dNTPs and salts, the genopure ds DNA purification kit for double-stranded DNA (Bruker Saxonia Analytik, Germany) was used. Purified PCR products were recovered in $5 \mu$ l elution buffer.

\section{PEX reactions}

In total, $5 \mu \mathrm{l}$ of the purified PCR product was mixed with the extension mix containing $10 \times$ reaction buffer (Amersham/Pharmacia), $1 \mathrm{U}$ of Thermosequenase (Amersham/ Pharmacia) and $20 \mathrm{pmol}$ of polymorphism detection primers (summarised in Table 2). Chain terminator $2^{\prime}, 3^{\prime}$ dideoxynucleotide triphosphates (ddNTP's) (Amersham/

Table 2 Sequences of primers and masses $M_{r}($ calc $)[M+H]+$ of extension products of MALDI-TOF MS assays

\begin{tabular}{|c|c|c|c|}
\hline CFTR polymorphism & Extension primer & Sequence $\left(5^{\prime} \rightarrow 3^{\prime}\right)$ & $M_{r}($ calc) $(D a)[M+H]+$ \\
\hline $\begin{array}{l}\text { Reaction } A \\
\text { Tn (IVS8) }\end{array}$ & $\begin{array}{l}\text { PEX } \mathrm{Tn}^{\mathrm{a}} \\
\text { T3 } \\
\text { T5 } \\
\text { T6 } \\
\text { T7 } \\
\text { T9 } \\
\text { T10 }\end{array}$ & $\begin{array}{l}\text { AAT AAT TCC CCA AAT CCC TGT T } \\
\text { AAT AAT TCC CCA AAT CCC TGT T }(A)_{3} d d C \\
\text { AAT AAT TCC CCA AAT CCC TGT T }(A)_{5} d d C \\
\text { AAT AAT TCC CCA AAT CCC TGT T }(A)_{6} d d C \\
\text { AAT AAT TCC CCA AAT CCC TGT T }(A)_{7} d d C \\
\text { AAT AAT TCC CCA AAT CCC TGT T }(A)_{9} d d C \\
\text { AAT AAT TCC CCA AAT CCC TGT T }(A)_{10} d d C\end{array}$ & $\begin{array}{r}6614.4 \\
7827.2 \\
8452.6 \\
8765.8 \\
9079.0 \\
9705.5 \\
10018.7\end{array}$ \\
\hline $1540 A>C(\operatorname{ex~} 10)$ & $\begin{array}{l}\text { PEX } 1540 A>G^{a} \\
\text { Allele } A \\
\text { Allele } G\end{array}$ & $\begin{array}{l}\text { GGC TCC AGT TCT CCC ATA ATC A } \\
\text { GGC TCC AGT TCT CCC ATA ATC ATddC } \\
\text { GGC TCC AGT TCT CCC ATA ATC A } d d C\end{array}$ & $\begin{array}{l}6631.4 \\
7207.8 \\
6903.6\end{array}$ \\
\hline $\begin{array}{l}\text { Reaction B } \\
\text { (TG)m (IVS8) }\end{array}$ & $\begin{array}{l}\text { PEX }(\mathrm{TG}) \mathrm{m}^{\mathrm{a}} \\
\text { (TG) } 8 \\
\text { (TG) } 9 \\
\text { (TG) } 10 \\
\text { (TG) } 11 \\
\text { (TG) } 12 \\
\text { (TG) } 13\end{array}$ & 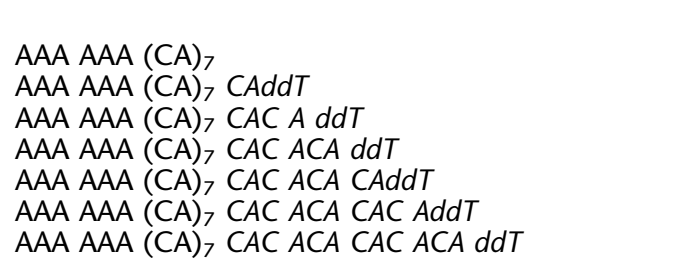 & $\begin{array}{l}6035.0 \\
6924.7 \\
7527.0 \\
8129.5 \\
8731.8 \\
9334.2 \\
9936.6\end{array}$ \\
\hline $\begin{array}{l}\text { Reaction C } \\
\text { (TG)mTn }\end{array}$ & $\begin{array}{l}\text { PEX (TG)mTn } \\
\text { (TG) } 12 \mathrm{~T} 3 \\
\text { (TG) } 13 \mathrm{~T} 3 \\
\text { (TG) } 11 \mathrm{~T} 5 \\
\text { (TG) } 12 \mathrm{~T} 5 \\
\text { (TG) } 13 \mathrm{TT} 5 \\
\text { (TG) } 13 \mathrm{~T} 6 \\
\text { (TG) } 8 \mathrm{T7} \\
\text { (TG) } 10 \mathrm{TT} \\
\text { (TG) } 11 \mathrm{TT} \\
\text { (TG) } 12 \mathrm{~T} 7 \\
\text { (TG) } 9 \text { T9 } \\
\text { (TG) } 10 \mathrm{TT} 9 \\
\text { (TG) } 11 \mathrm{~T} 9 \\
\text { (TG) } 9 \text { T10 }\end{array}$ & $\begin{array}{l}\text { AAT AAT TCC CCA AAT CCC TGT T } \\
\text { AAT AAT TCC CCA AAT CCC TGT T } A_{3}(C A)_{12} d d T \\
\text { AAT AAT TCC CCA AAT CCC TGT T } A_{3}(C A)_{13} d d T \\
\text { AAT AAT TCC CCA AAT CCC TGT T } A_{5}(C A)_{11} d d T \\
\text { AAT AAT TCC CCA AAT CCC TGT T } A_{5}(C A)_{12} d d T \\
\text { AAT AAT TCC CCA AAT CCC TGT T } A_{5}(C A)_{13} d d T \\
\text { AAT AAT TCC CCA AAT CCC TGT T } A_{6}(C A)_{13} d d T \\
\text { AAT AAT TCC CCA AAT CCC TGT T } A_{7}(C A)_{8} d d T \\
\text { AAT AAT TCC CCA AAT CCC TGT T } A_{7}(C A)_{10} d d T \\
\text { AAT AAT TCC CCA AAT CCC TGT T } A_{7}(C A)_{11} d d T \\
\text { AAT AAT TCC CCA AAT CCC TGT T } A_{7}(C A)_{12} d d T \\
\text { AAT AAT TCC CCA AAT CCC TGT T } A_{9}(C A)_{9} d d T \\
\text { AAT AAT TCC CCA AAT CCC TGT T } A_{9}(C A)_{10} d d T \\
\text { AAT AAT TCC CCA AAT CCC TGT T } A_{9}(C A)_{11} d d T \\
\text { AAT AAT TCC CCA AAT CCC TGT T } A_{10}(C A)_{9} d d T\end{array}$ & $\begin{array}{r}6614.4 \\
15070.0 \\
15672.4 \\
15094.0 \\
15696.4 \\
16298.8 \\
16612.0 \\
13913.2 \\
15118.0 \\
15720.4 \\
16322.8 \\
15142.0 \\
15744.4 \\
16346.8 \\
15455.3\end{array}$ \\
\hline $\begin{array}{l}\text { Reaction D: } \\
\quad \text { 2694T }>\text { G (ex 14a) }\end{array}$ & $\begin{array}{l}\text { PEX 2694T > G } \\
\text { Allele T } \\
\text { Allele G }\end{array}$ & $\begin{array}{l}\text { TGG AAC ACA TAC CTT CGA TAT ATT AC } \\
\text { TGG AAC ACA TAC CTT CGA TAT ATT AC } d d T \\
\text { TGG AAC ACA TAC CTT CGA TAT ATT ACG GddT }\end{array}$ & $\begin{array}{l}7914.3 \\
8201.5 \\
8859.9\end{array}$ \\
\hline $4521 \mathrm{G}>\mathrm{A}(\mathrm{ex} 24)$ & $\begin{array}{l}\text { PEX } 4521 \mathrm{G}>\mathrm{A}^{\mathrm{a}} \\
\text { Allele } \mathrm{G} \\
\text { Allele A }\end{array}$ & $\begin{array}{l}\text { GTC TCC TCT TTC AGA GCA GCA AT } \\
\text { GTC TCC TCT TTC AGA GCA GCA ATC } d d T \\
\text { GTC TCC TCT TTC AGA GCA GCA AT } d d T\end{array}$ & $\begin{array}{l}6975.6 \\
7552.0 \\
7262.8\end{array}$ \\
\hline
\end{tabular}

${ }^{a}$ Extension primer binds to the reverse strand of the CFTR gene. 
Pharmazia) were used together with regular dNTPs (Roche) in the following combinations and concentrations: dATP and dTTP (200 $\mu \mathrm{M}$ each) and $200 \mu \mathrm{M}$ ddCTP for extension primer PEX Tn and PEX 1540A > G (Reaction A); dATP and dCTP ( $1 \mathrm{~mm}$ each) and $200 \mu \mathrm{M}$ ddTTP for primer PEX (TG)mTn (Reaction B); dATP and dCTP (200 $\mu \mathrm{M}$ each) and $200 \mu \mathrm{M}$ ddTTP for primer PEX (TG)m (Reaction C); and dGTP and dCTP $(200 \mu \mathrm{M}$ each) and $200 \mu \mathrm{M}$ ddTTP for multiplexing primers PEX 2694T $>$ G and PEX 4521G $>$ A (Reaction D). Final reaction volumes were $10 \mu \mathrm{l}$. Cycling conditions were $2 \mathrm{~min}$ at $94^{\circ} \mathrm{C}$ followed by 40 cycles of $10 \mathrm{~s}$ at $94^{\circ} \mathrm{C}, 15 \mathrm{~s}$ at $61^{\circ} \mathrm{C}, 45 \mathrm{~s}$ at $72^{\circ} \mathrm{C}$ and a final extension time of $5 \mathrm{~min}$ at $72^{\circ} \mathrm{C}$. Excess salts and nucleotides were removed using the genopure oligo DNA purification kit (Bruker Saxonia Analytik, Germany). Purified extension products and residual primers were eluted in $10 \mu$ l elution buffer and subsequently subjected to MALDI-TOF MS.

\section{Mass spectrometry}

The matrix for PEX analysis consisted of a mixture of $0.3 \mathrm{M}$ 3-hydroxypicolinic acid (3-HPA), $0.5 \mathrm{M}$ picolinic acid and $0.3 \mathrm{M}$ ammonium fluoride with ratio at a 9:1:1 (v:v:v). Matrix solution $(1 \mu \mathrm{l})$ was pipetted on an AnchorChip ${ }^{\mathrm{TM}}$ sample target (Bruker Daltonik, Germany; anchor size: $400 \mu \mathrm{m})$ and allowed to dry at room temperature. Purified PEX reaction product $(1 \mu \mathrm{l})$ was added to the dried matrix spots and again dried at room temperature. The target was subsequently introduced into the source region of a Ultraflex mass spectrometer with SCOUT MTP ion source (Bruker Daltonik, German), operated in linear mode with $25 \mathrm{kV}$. Theoretical average masses of the positively charged $[\mathrm{M}+\mathrm{H}]+\mathrm{PEX}$ primers and the resulting PEX reaction products were calculated according to their nucleotide compositions using Mongo Oligo Mass Calculator v.2.06 (http://medlib.med.utah.edu/masspec/mongo.htm). The instrument was calibrated using single-stranded DNA standards between 4 and $8 \mathrm{kDa}$ and a protein standard between 3 and $25 \mathrm{kDa}$, respectively.

\section{Results}

The study set comprised the analysis of 20 individuals (40 chromosomes), representing nine different haplotypes out of the 14 (TG)mTn haplotypes described so far in literature, ${ }^{1-6}$ and 17 different (TG)mTn haplotype combinations. Table 2 presents an overview of the theoretical PEX products of the known (TG)mTn haplotypes and the genotypes of SNP 1540A > G (p.M470V) in exon 10, SNP $2694 \mathrm{~T}>\mathrm{G}$ in exon 14a and SNP 4521G $>\mathrm{A}$ in exon 24. Figure 1 shows mass spectra of PEX reaction products from patient number 9 .

Reaction A in patient 9 (Figure 1a) detects simultaneously (biplex) the length of the T-repeat and the genotype for the $1540 \mathrm{~A}>\mathrm{G}$ polymorphism. The detection primer for the T-repeat (6625.9 Da) was extended by five
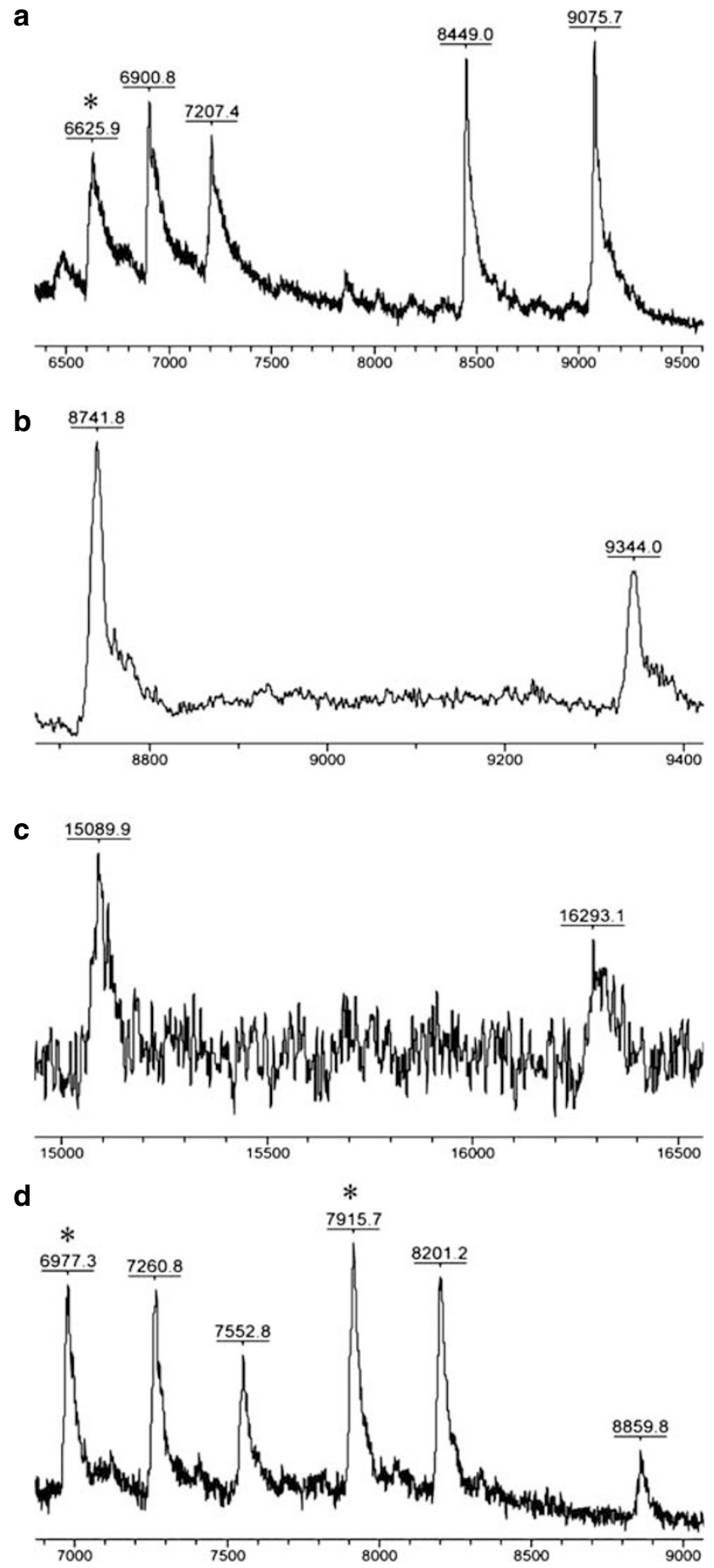

Figure 1 MALDI-TOF mass spectra of PEX products for detection of CFTR polymorphisms in IVS8 and exons 10, 14a and 24 in patient 9. (a) Reaction A, heterozygosity for a T5 and T7 allele as well as heterozygotsity for $1540 \mathrm{~A}>\mathrm{G}$. (b) Reaction B, heterozygosity for (TG) 11 and (TG) 12 alleles. (c) Reaction C, determination of the overall lengths of the (TG)mTn alleles, and (d) Reaction D, heterozygosity for $2694 \mathrm{~T}>\mathrm{G}$ and $4521 \mathrm{G}>\mathrm{A}$. Asterisks indicate unextended PEX primers. 
bases $(8449.0 \mathrm{Da})$ and by seven bases $(9075.7 \mathrm{Da})$, respectively (Figure 1a), thus indicating a genotype with one T5 and one T7 allele (Table 3). The extension of the second detection primer $(6625.9 \mathrm{Da})$ results also in a split peak (6900.8 Da allele G and 7207.4 Da allele A, Figure 1a), indicating heterozygosity for the SNP 1540A $>$ G (Table 4). The masses of both detection primers differ in only $27 \mathrm{Da}$, hence they cannot properly be resolved by MALDI-MS and a single peak with the average mass of $6625.9 \mathrm{Da}$ is observed.

Figure $1 \mathrm{~b}$ shows the mass spectra of the Reaction B in patient 9 for length determination of the (TG)m repeat. Two PEX reaction products are observed with a mass of 8741.8 and $9344.0 \mathrm{Da}$, indicating a heterozygous genotype for one (TG)11 and one (TG)12 allele; in addition, a peak with the mass of 6041.1 Da (not shown) indicates unextended detection primer.

The haplotypes of the (TG)mTn repeat of patient 9 were deduced using the Reaction $\mathrm{C}$ measuring the overall length of the (TG)mTn repeat of both alleles (Figure 1c). Three peaks of $6624.0 \mathrm{Da}$ (not shown; unextended detection primer), 15089.9 and $16293.1 \mathrm{Da}$ are measured, which unambiguously assign the haplotypes (TG)11T5 and (TG)12T7 to the patient (Tables 2 and 3). Haplotypes (TG)11T7 and (TG)12T5 are not to be considered, as this combination would lead to expected peak masses of 15720.4 and $15696.4 \mathrm{Da}$ (according to Table 2, Reaction C). The haplotypes of all 20 patients were assigned the same way as has been shown stepwise for patient 9 (Figure 1) and are summarised in Table 3.

PEX reactions (Reaction D) were also used for biplex detection of the polymorphisms $2694 \mathrm{~T}>\mathrm{G}$ and $4521 \mathrm{G}>\mathrm{A}$ in exon 14a and exon 24, respectively, of the CFTR gene. As seen in Figure 1d, for the first detection primer (6977.3 Da), two PEX reaction products of 7260.8 and $7552.8 \mathrm{Da}$ are resolved, indicating a heterozygous genotype for SNP 4521G $>$ A (Table 4). The second detection primer $(7915.7 \mathrm{Da})$ is converted to a pair of peaks at 8201.2 and $8859.8 \mathrm{Da}$ (Figure 1d). Thus, this patient is also heterozygous for SNP 2694T $>$ G (Table 4). The results of the SNP genotypes of the other 19 individuals are summarised in Table 4. All haplotypes of the (TG)mTn repeats and genotypes of the DNA variations were assigned according to PEX reaction product masses. Our PEX clean-up protocol and the inclusion of ammonium fluoride in the matrix was sufficient to suppress alkali metal ion adduction to an extent, that did not interfere with data analysis and interpretation..$^{29}$ Observed $M_{\mathrm{r}}(\exp )$ values and their differences to the expected $M_{\mathrm{r}}$ (calc) values are listed in Table 3 and 4. The accuracy of the observed values compared to $M_{\mathrm{r}}$ (calc) ranged from -9.5 to $+12.2 \mathrm{Da}$ for Reaction A (mean $0.253 \pm 4.54$ ), from -8.8 to $+13.2 \mathrm{Da}$ for Reaction $\mathrm{B}$ (mean 2.12 \pm 5.45 ), from -29.7 to +37.6 Da for Reaction C (mean $4.38 \pm 13.6$ ) and -4.1 to $+7.8 \mathrm{Da}$ for Reaction D (mean $1.78 \pm 2.82$ ). The variation of $M_{\mathrm{r}}(\exp )$ did not exceed

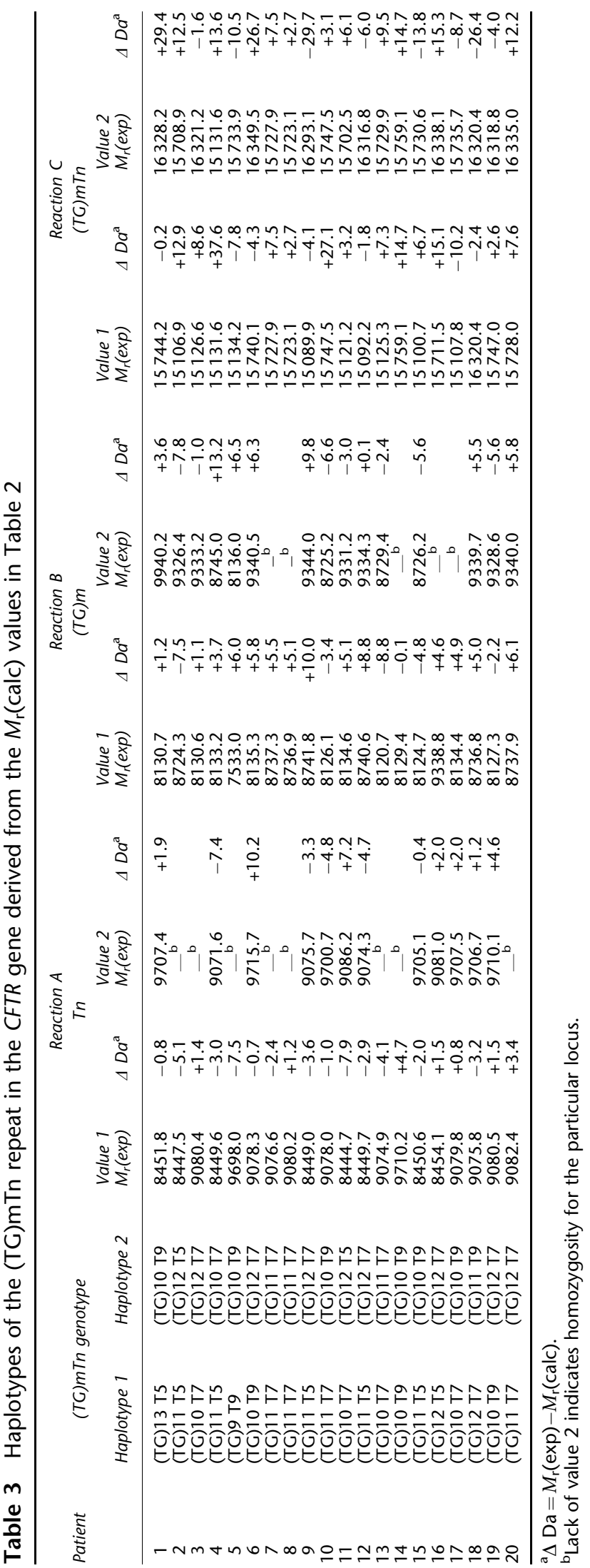


$0.15 \%$ (Reaction A, B and D) and $0.25 \%$ (Reaction C), respectively, of $M_{\mathrm{r}}$ (calc). The higher range in Reaction C is owing to a decreased resolution of the long PEX products caused by the MALDI process and the poor sensitivity for those long PEX products. Thus, a correct interpretation of the peaks is allowed in any case, because the mass difference of the allele-specific products of the PEX is at all times at least one nucleotide (average mass $309 \mathrm{Da}$ ).

\section{Discussion}

We present a rapid and reliable method for the determination of polymorphic loci in the CFTR gene that may contribute to the development of CFTR-related diseases by affecting the correct splicing of CFTR pre-mRNA. The polymorphic (TG)mTn locus plays a predominant role in the alternative splicing of CFTR exon 9; in addition, three common SNPs have also been shown to modulate correct splicing of CFTR exon 9, 12 and $14 \mathrm{a}^{26}$

The 5T allele of the Tn tract in intron 8 is known as a CFTR mutation with incomplete penetrance and associated with CBAVD and milder forms of CF. Recent studies showed that penetrance is affected by the (TG)m repeat preceding the Tn tract, pointing out the importance of not only properly assessing the length of the Tn tract but also of the (TG)m repeat for diagnostic purposes. As the two repeats act in concert when modulating correct exon 9 splicing, reliable haplotyping is an additional prerequisite for the meaningful genetic testing of this locus. Groman et $a l^{10}$ demonstrated that (TG)12T5 and (TG)13T5 alleles are present with increased frequency in patients affected by CBAVD and mild CF, whereas healthy individuals carrying a T5 allele and a severe mutation in trans are more likely to have a (TG)11T5 allele, suggesting that the (TG)11T5 allele is generally benign. This is supported by studies showing a positive correlation between the length of the (TG)m repeat and the proportion of exon 9 skipping ${ }^{11}$ due to the facilitated binding of the splicing suppressor TDP-43. ${ }^{2,3}$

However, the fact that $9 \%$ of affected persons examined by Groman $e a^{10}$ carried a (TG) $11 \mathrm{~T} 5$ allele and $22 \%$ of the healthy individuals had a (TG)12T5 allele indicates that the penetrance of $\mathrm{T} 5$ alleles does not only depend on the length of the (TG)m repeat but also on additional cis or trans acting factors.

An influence of the SNP 1540A $>$ G in CFTR exon 10 on the penetrance of $\mathrm{T} 5$ alleles has been proposed in several studies, ${ }^{11,30}$ yet could not be proven by Groman et al. However, the polymorphic form of this locus as well as of other CFTR SNPs (2694T $>\mathrm{G}$ in exon 14a and $4521 \mathrm{G}>\mathrm{A}$ in exon 24) changes regulatory sequence motifs of exonic splice enhancers of the CFTR gene and is significantly associated with CFTR exon 9 and exon 12 skipping. ${ }^{26}$ Thus, these SNPs may act in concert with the (TG)mTn repeat when influencing the final amount of functional CFTR 
mRNA and thereby may contribute to the penetrance of the $\mathrm{T} 5$ allele as disease-causing mutation.

Several assays for the analysis of either the Tn repeat alone or both the (TG)m and Tn repeat have been proposed. However, most of them only allow the determination of the Tn repeat, and/or are labour-intensive and difficult to interpret in samples being heterozygous for both the Tn and (TG)m repeats.

Methods for the determination of the Tn repeat alone are all based on the preliminary amplification of exon 9 and its intronic boundaries. Subsequent evaluation of the PCR product is accomplished by nested PCR with a forward primer that binds to some extent to the (TG)m repeat and contains a stretch of five thymidines at the $3^{\prime}$-end, followed by XmnI restriction and nondenaturating polyacrylamide gel electrophoresis. ${ }^{7}$ Alternatively, allele-specific oligonucleotide (ASO) hybridisation with probes that recognise 5,7 or 9 thymidines is performed on the PCR products. ${ }^{31}$ Similarly, commercially available kits like the Cystic fibrosis v3 5/7/9T OLA ASR kit (Abbott diagnostics, USA) are also based on hybridization and subsequent ligation of oligonucleotides specific for 5,7 or 9 thymidines to PCR products. Finally, the allele-specific PCR assay developed by Friedman et $a l^{32}$ uses three PCR reactions with reverse primers specific for either 5, 7 or 9 thymidines, resulting in different amplification patterns depending on the genotype. An enhanced version of this method uses three specific reverse primers, each labelled with a different fluorescent tag. This method also allows, to some degree, the detection of the allelic variability in the (TG)m repeat. ${ }^{33}$ However, beside from being fairly labour- and material-intensive, these methods have the disadvantage that they fail to detect the rare 3T, and some the $6 \mathrm{~T}$ and 10T alleles, making them inappropriate tools for accurate and reliable analysis of the Tn repeat, as they may suggest homozygosity for one of the common Tn variants when in reality a 3T, 6T or $10 \mathrm{~T}$ allele is present. In addition, as penetrance of $\mathrm{T} 5$ alleles seems to depend on the (TG)m repeat, results of these assays are only partly informative for genetic testing, and supplementary determination of the $(\mathrm{TG}) \mathrm{m}$ repeat is indicated after the identification of a T5 allele. Sequencing-based methods include protocols in which the (TG)mTn region is first analysed using DGGE or
SSCP/HD (single-strand conformation polymorphism/heteroduplex) analysis, followed by sequencing of differing banding patterns, $, 17,19,27$ and protocols which take advantage of direct sequencing. ${ }^{10,20,34}$ However, these sequencing-based methods have the drawback that electropherograms may be more difficult to interpret compared to the method presented here. As different alleles are displayed in the same electropherogram, adjacent polymorphic repeats like the (TG)mTn repeat are difficult to resolve, making the determination of repeat lengths and particularly haplotypes a complex issue. This is especially true for samples heterozygous for both the (TG)m and Tn repeats leading to shifts and thus to double peaks in electropherograms. ${ }^{20}$ The determination of haplotypes is intricate in these cases and needs expert knowledge for correct assessment. Additionally, microdeletions neighbouring the (TG)mTn locus may further hamper the interpretation, as they lead to additional shifts in electropherograms. Haplotypes can either be inferred from genotypes by statistical approaches and family studies, or by various molecular techniques including physical separation of chromosomes or analysis of individual DNA molecules. ${ }^{35,36}$ However, these techniques may either deliver ambiguous results or are not well-suited for highthroughput analyses. Easier-to-perform molecular haploytyping techniques include allele-specific amplification ${ }^{37}$ and combination of allele-specific amplification with pyrosequencing $^{38}$ or MALDI-TOF-MS, ${ }^{39}$ which, however, are not convenient approaches for haplotyping the (TG)mTn repeat due to the many existing alleles. Recently, an assay based on melting curve analysis was presented for the direct molecular haplotyping of (TG)mTn repeat. ${ }^{5}$ However, if this assay is able to detect haplotypes in combination with T3, T4, T6 and TG8 alleles remains to be elucidated.

In the present study, we exploited the advantages of MALDI-TOF MS to circumvent the problems associated with the interpretation of complex electropherograms. In MALDI-TOF MS, different lengths of polymorphic repeats do not lead to double peaks and overlay of sequences as in electropherograms, but rather to distinct masses, making data interpretation rapid and reliable. Furthermore, the principle of distinct masses and the ease

Table 5 Sequence variants located in PEX primer-binding sites

\begin{tabular}{lll}
\hline Reaction & Primer & Sequence variants \\
\hline A & PEX Tn & $1342-2 \mathrm{~A}>\mathrm{C}, 1342-2$ delAG, 1342-1G $>$ C, 1352A $>$ T \\
& PEX 1540 A $>$ G & 1548 del, $1552 \mathrm{G}>$ A \\
B & PEX (TG)m & $1342-13 \mathrm{G}>\mathrm{T}, 1342-11 \mathrm{TT}>\mathrm{G}$ \\
C & PEX (TG)mTn & $1342-2 \mathrm{~A}>\mathrm{C}, 1342-2$ delAG, 1342-1G $>$ C, 1352A $>$ T \\
D & PEX 2694T $>$ G & $2669 \mathrm{G}>\mathrm{A}, 2670 \mathrm{G}>\mathrm{A}, 2679 \mathrm{C}>\mathrm{A}, 2683 \mathrm{C}>\mathrm{T}, 2684 \mathrm{G}>\mathrm{T}, 2691 \mathrm{~T}>\mathrm{C}$ \\
\hline
\end{tabular}

Source: http://www.genet.sickkids.on.ca/cftr/ 
of data interpretation have the advantage that rare or yet unknown repeat lengths and haplotypes are detected with the same probability as common alleles. Principally, Reaction $C$ would be sufficient to haplotype the (TG)mTn repeat. However, by performing independent reactions for each repeat as well as for the haplotype, our method becomes more robust and reliable than other methods, as erroneous genotyping due to overlooked peaks will be detected when assembling the haplotype. In addition, the method presented here is less cost- and labour-intensive than other methods including direct sequencing.

Although we tested only 17 out of the possible 98 combinations of known (TG)mTn repeats, we expect that none of the possible haplotype combinations should be missed; first, given the fact that different genotypes are reflected by mass differences of at least $289.2 \mathrm{Da}$, the chance of getting unassignable results due to poor accuracy and/or resolution is minimised. Second, the redundancy obtained by performing three independent reactions decreases the risk of incorrect haplotyping to an absolute minimum, as for example overlooked peaks will be detected when assembling the haplotype. Possible limitations of the method include sequence variants of the primer-binding sites. For PCR - primers, we found a single variant located in the $5^{\prime}$ part of primer CF24B $(4655 \mathrm{~T}>\mathrm{G})$, which probably does not affect PCR efficiency (http:// www.genet.sickkids.on.ca/cftr/). However, this risk applies for all PCR-based protocols. For PEX-primer-binding sites, all known variants are summarised in Table 5 .

In conclusion, our assay allows the analysis of all five cis-acting factors known to influence the correct splicing of CFTR pre-mRNA within one working day, making it an adequate assay for high-throughput investigations of factors that may not only modulate disease penetrance of loci such as the T5 allele but which may also contribute to the variable disease expression of patients carrying the same CFTR genotype. Thus, our method also facilitates the work of clinicians involved in the diagnosis of non-classic CF by substantiating the diagnosis and allowing precise counselling. The method can easily be extended to any other locus of interest and be combined with published MALDI-TOF MS assays for CFTR genotyping. ${ }^{24,25}$

\section{Acknowledgements}

We are indebted to all patients, family members and clinicians involved for their cooperation and collaboration. This work was supported by the Swiss National Foundation, Grant No.: 3200066767.01 .

\section{References}

1 Chu CS, Trapnell BC, Curristin S, Cutting GR, Crystal RG: Genetic basis of variable exon 9 skipping in cystic fibrosis transmembrane conductance regulator mRNA. Nat Genet 1993; 3: 151-156.
2 Buratti E, Baralle FE: Characterization and functional implications of the RNA binding properties of nuclear factor TDP-43, a novel splicing regulator of CFTR exon 9. J Biol Chem 2001; 276: 36337-36343.

3 Buratti E, Dork T, Zuccato E, Pagani F, Romano M, Baralle FE: Nuclear factor TDP-43 and SR proteins promote in vitro and in vivo CFTR exon 9 skipping. EMBO J 2001; 20: 1774-1784.

4 Disset A, Michot C, Harris A, Buratti E, Claustres M, TufferyGiraud S: A T3 allele in the CFTR gene exacerbates exon 9 skipping in vas deferens and epididymal cell lines and is associated with congenital bilateral absence of vas deferens (CBAVD). Hum Mutat 2005; 25: 72-81.

5 Millson A, Pont-Kingdon G, Page S, Lyon E: Direct molecular haplotyping of the IVS-8 Poly(TG) and PolyT repeat tracts in the cystic fibrosis gene by melting curve analysis of hybridization probes. Clin Chem 2005; 51: 1619-1623.

6 Viel M, Leroy C, Des GM, Claustres M, Bienvenu T: Novel length variant of the polypyrimidine tract within the splice acceptor site in intron 8 of the CFTR gene: consequences for genetic testing using standard assays. Eur J Hum Genet 2005; 13: 136-138.

7 Chillon M, Casals T, Mercier B et al: Mutations in the cystic fibrosis gene in patients with congenital absence of the vas deferens. N Engl J Med 1995; 332: 1475-1480.

8 Zielenski J, Patrizio P, Corey $\mathrm{M}$ et al: CFTR gene variant for patients with congenital absence of vas deferens. Am J Hum Genet 1995; 57: 958-960.

9 Mak V, Zielenski J, Tsui LC et al: Proportion of cystic fibrosis gene mutations not detected by routine testing in men with obstructive azoospermia. JAMA 1999; 281: 2217-2224.

10 Groman JD, Hefferon TW, Casals T et al: Variation in a repeat sequence determines whether a common variant of the cystic fibrosis transmembrane conductance regulator gene is pathogenic or benign. Am J Hum Genet 2004; 74: 176-179.

11 Cuppens $\mathrm{H}$, Lin W, Jaspers $\mathrm{M}$ et al: Polyvariant mutant cystic fibrosis transmembrane conductance regulator genes. The polymorphic (Tg)m locus explains the partial penetrance of the T5 polymorphism as a disease mutation. J Clin Invest 1998; 101: 487-496.

12 Buratti E, Brindisi A, Pagani F, Baralle FE: Nuclear factor TDP-43 binds to the polymorphic TG repeats in CFTR intron 8 and causes skipping of exon 9: a functional link with disease penetrance. $A m$ J Hum Genet 2004; 74: 1322-1325.

13 Chu CS, Trapnell BC, Murtagh Jr JJ et al: Variable deletion of exon 9 coding sequences in cystic fibrosis transmembrane conductance regulator gene mRNA transcripts in normal bronchial epithelium. EMBO J 1991; 10: 1355-1363.

14 Cuppens H, Marynen P, De Boeck C, Cassiman JJ: Detection of $98.5 \%$ of the mutations in 200 Belgian cystic fibrosis alleles by reverse dot-blot and sequencing of the complete coding region and exon/intron junctions of the CFTR gene. Genomics 1993; 18: 693-697.

15 Dork T, Fislage R, Neumann T, Wulf B, Tummler B: Exon 9 of the CFTR gene: splice site haplotypes and cystic fibrosis mutations. Hum Genet 1994; 93: 67-73.

16 Cazeneuve C, Beldjord C, Kaplan JC, Bienvenu T: Diagnostic usefulness of the polymorphism of the GT dinucleotide and the polythymidine tract in intron 8 of the cystic fibrosis transmembrane conductance regulator (CFTR) gene. Ann Genet 1995; 38: 202-205.

17 Costes B, Girodon E, Ghanem N et al: Frequent occurrence of the CFTR intron 8 (TG)n 5T allele in men with congenital bilateral absence of the vas deferens. Eur J Hum Genet 1995; 3: 285-293.

18 Arduino C, Gallo M, Brusco A et al: Polyvariant mutant CFTR genes in patients with chronic pancreatitis. Clin Genet 1999; 56: 400-404.

19 Pallares-Ruiz N, Carles S, Des GM et al: Complete mutational screening of the cystic fibrosis transmembrane conductance regulator gene: cystic fibrosis mutations are not involved in healthy men with reduced sperm quality. Hum Reprod 1999; 14: $3035-3040$. 
20 Lucarelli M, Grandoni F, Rossi T, Mazzilli F, Antonelli M, Strom R: Simultaneous cycle sequencing assessment of (TG)m and Tn tract length in CFTR gene. Biotechniques 2002; 32: 540-547.

21 Werner M, Sych M, Herbon N, Illig T, Konig IR, Wjst M: Large-scale determination of SNP allele frequencies in DNA pools using MALDI-TOF mass spectrometry. Hum Mutat 2002; 20: $57-64$.

22 Bray MS, Boerwinkle E, Doris PA: High-throughput multiplex SNP genotyping with MALDI-TOF mass spectrometry: practice, problems and promise. Hum Mutat 2001; 17: 296-304.

23 Corona G, Toffoli G: High throughput screening of genetic polymorphisms by matrix-assisted laser desorption ionization time-of-flight mass spectrometry. Comb Chem High Throughput Screen 2004; 7: 707-725

24 Braun A, Little DP, Koster H: Detecting CFTR gene mutations by using primer oligo base extension and mass spectrometry. Clin Chem 1997; 43: 1151-1158.

25 Wang Z, Milunsky J, Yamin M, Maher T, Oates R, Milunsky A: Analysis by mass spectrometry of 100 cystic fibrosis gene mutations in 92 patients with congenital bilateral absence of the vas deferens. Hum Reprod 2002; 17: 2066-2072.

26 Steiner B, Truninger K, Sanz J, Schaller A, Gallati S: The role of common single-nucleotide polymorphisms on exon 9 and exon 12 skipping in nonmutated CFTR alleles. Hum Mutat 2004; 24: $120-129$.

27 Liechti-Gallati S, Schneider V, Neeser D, Kraemer R: Two buffer PAGE system-based SSCP/HD analysis: a general protocol for rapid and sensitive mutation screening in cystic fibrosis and any other human genetic disease. Eur J Hum Genet 1999; 7: 590-598.

28 Zielenski J, Rozmahel R, Bozon D et al: Genomic DNA sequence of the cystic fibrosis transmembrane conductance regulator (CFTR) gene. Genomics 1991; 10: 214-228.

29 Cheng SW, Chan TW: Use of ammonium halides as co-matrices for matrix-assisted laser desorption/ionization studies of oligonucleotides. Rapid Commun Mass Spectrom 1996; 10: 907-910.
30 de Meeus A, Guittard C, Desgeorges M, Carles S, Demaille J, Claustres M: Linkage disequilibrium between the M470V variant and the IVS8 polyT alleles of the CFTR gene in CBAVD. J Med Genet 1998; 35: 594-596.

31 Kiesewetter S, Macek Jr M, Davis C et al: A mutation in CFTR produces different phenotypes depending on chromosomal background. Nat Genet 1993; 5: 274-278.

32 Friedman KJ, Heim RA, Knowles MR, Silverman LM: Rapid characterization of the variable length polythymidine tract in the cystic fibrosis (CFTR) gene: association of the 5T allele with selected CFTR mutations and its incidence in atypical sinopulmonary disease. Hum Mutat 1997; 10: 108-115.

33 Strasberg PM, Friedman KJ, McGlynn-Steele L, Zielenski J, Ray PN: Rapid characterization of both the variable length 5,7 or 9 polythimidine (T) tract in intron 8 and the adjacent $\mathrm{CA}$ repeat unit of the CFTR gene: use in DNA diagnostic. Am J Hum Genet 1997; 4 (Suppl 61): A2038.

34 Jezequel P, Dubourg C, Le Lannou D et al: Molecular screening of the CFTR gene in men with anomalies of the vas deferens: identification of three novel mutations. Mol Hum Reprod 2000; 6: $1063-1067$

35 Yan H, Papadopoulos N, Marra G et al: Conversion of diploidy to haploidy. Nature 2000; 403: 723-724.

36 Douglas JA, Boehnke M, Gillanders E, Trent JM, Gruber SB: Experimentally-derived haplotypes substantially increase the efficiency of linkage disequilibrium studies. Nat Genet 2001; 28: 361-364.

37 Ruano G, Kidd KK: Direct haplotyping of chromosomal segments from multiple heterozygotes via allele-specific PCR amplification. Nucleic Acids Res 1989; 17: 8392.

38 Odeberg J, Holmberg K, Eriksson P, Uhlen M: Molecular haplotyping by pyrosequencing. Biotechniques 2002; 33: 1104, 1106, 1108

39 Tost J, Brandt O, Boussicault F et al: Molecular haplotyping at high throughput. Nucleic Acids Res 2002; 30: e96. 